\title{
Vitamin Practices and Ideologies of Health and the Body
}

\author{
Maryann McCabe \\ Cultural Connections LLC, and \\ University of Rochester
}

\author{
Antonella Fabri \\ Caleidoscopio Ethnographic Research
}

This article addresses people in the United States by examining beliefs and practices among people who take vitamins and supplements. The continuing rise of vitamin consumption calls for explanation given the lack of scientific consensus about the efficacy of vitamin pills in preventing disease and improving health. Taking vitamins contests biomedicine professionals and represents the choice for an alternative health practice that involves magical thinking, the emotions and sensory knowledge. Vitamins are self-medicating devices that lead to a culturally constituted experience of the self as a productive and whole person in a capitalist society. We pursue the notion of tactics to articulate the relationship between agency and structure. Vitamin practices reflect a nuanced concept of agency that shows how people navigate broader processes converging in the marketplace. Operating within this wider field, practices are transformative and lead to social change.

\section{INTRODUCTION}

Most people in the United States take vitamins or supplements on a regular basis. Only 12 percent of the population does not take any vitamins, according to a Yankelovich survey conducted in the year 2000. ${ }^{1}$ Given lack of scientific consensus about the efficacy of vitamin pills in preventing disease and improving health, the widespread practice of taking vitamins remains a curiosity. Why are people so committed to vitamin use? Sales in this $\$ 27$ billion industry have been rising annually, according to Nutrition Business Journal (2010). ${ }^{2,3}$ Growth has been spurred by continuous new product development especially in the supplement market. The United States is the leading vitamin consumer in the world, followed by Western Europe and Japan, with China expected to surpass these markets in the future.

This article examines vitamin practices among U.S. consumers in order to understand cultural beliefs and values that motivate increasing use of these non-food additions to the national diet. We look at consumer beliefs in relation to lack of scientific proof concerning efficacy in order to explore how taking vitamin pills involves magical thinking. In a society 
which privileges scientific thinking, the question arises why magical thinking constitutes part of the consumer's approach to something as important as health. We draw out implications of taking vitamins and engaging in magical thinking in terms of the definition of personhood. This perspective on vitamin practices through the senses and emotions leads to unpacking the notion of wholeness and how people know that vitamins help to achieve the state of health they desire.

Health is an empirical fact for each person who takes vitamin pills as well as a social fact or ideological proposition (Metzl, 2010). We consider vitamin practices in light of historical processes to show how power wielded by the pharmaceutical industry, the medical establishment, and government impinge on people's decisions to use vitamins. At the same time, we indicate how consumers navigate through the marketplace where all these forces converge.

Our analysis of vitamin practices proceeds from practice theory with its focus on the relationship between agency and structure (Bourdieu, 1977; Giddens, 1979; Ortner, 1984). Ahearn (2001) notes that practice theory has paid insufficient attention to how social change occurs and calls for perspectives that would indicate how "actors manage at times to transform the systems that produce them" (2001:120). Theoretical discussions of agency typically compare the Western conception of agency as internal or within the individual to the 'other' or nonWestern conception of agency as external or within the social milieu. We aim to develop a more nuanced concept of agency that addresses change by showing how agency shifts in different social and political contexts in which the person is engaged.

As personal systems designed to provide nutrients perceived missing from the body, vitamin practices are creative acts of cultural production. Creativity is both constrained and enabled by structure or the wider field in which actions are embedded (Moeran, 2011). Using the concept of tactics to articulate the relationship between agency and structure (de Certeau, 1984), we will look at tactics people use in developing personal systems of vitamin consumption and indicate how subjectivity of the vitamin user has emerged over time since vitamins were discovered. Subjectivity can change when people make decisions about their lives in the context of broader social, economic and political processes (Krause, 2009). We explore subjectivity arising from people dealing with the vitamin marketplace and ideologies about the body and health.

\section{METHODOLOGY}

Data for this paper on vitamin practices come from three market research projects that we conducted for two vitamin and supplement manufacturers during the years 2000-2008. One company, an international pharmaceutical corporation headquartered in Europe, was exploring the possibility of introducing its line of vitamins to the U.S. marketplace. The other company, a U.S. subsidiary of a Japanese vitamin manufacturer, wanted to redesign packaging and retail display for its brand of vitamins.

The authors are anthropologists whose careers have involved working with companies to help them gain insight into the meaning of objects of material culture in the everyday lives of consumers. Our relationship with both companies developed through McCabe's consulting practice, and Fabri joined the research team for two of the three projects.

As anthropologists, we used ethnographic research methods including interviews in the home with home tours and shopalongs plus homework assignments like journals and collages. The size and scope of the three projects differed to some extent depending on the learning objectives of each project, but in general the objectives were oriented to identifying cultural assumptions, beliefs, metaphors and values underlying vitamin practices. For the largest project, there were 40 
respondents who were interviewed in Boston, Seattle, Chicago, and Los Angeles. In the two smaller projects, 16 and 12 respondents respectively were interviewed in Chicago and Los Angeles. Thus, a total of 68 respondents participated in the three projects. They were selected to capture a range of age (25-65 years old), gender, ethnicity, socio-economic status, and vitamin usage (moderate to heavy intake of vitamins and supplements).

Both of us have taken vitamins at different periods across our life span. It was interesting to conduct this research and learn about other people's experience with vitamins as well as turn a reflexive gaze upon our own practices. As is typical in research situations where you study behavior in your own society, we gained insight into ourselves, others and the context of vitamin use.

\section{BELIEF IN DEFICIENCY AND THE NEED FOR VITAMINS}

Vitamin practices are based on a core belief in deficiency that our bodies do not get all the nutrients they need from the food we eat. Wendy, a 35 year old mother of three children $(6,4$ and 1 years old), says that she carefully watches what the family eats but still doesn't know if they get all the vitamins they need so vitamin pills are a fool proof way of making sure they do. She started taking multivitamins at the time of her first pregnancy. Now she, her husband and the children take multivitamins every day.

From the consumer perspective, vitamin pills replace what the body is missing and restore balance in the body. There is an assumption about deficiency that even if we eat well, we can never get the exact number and proportion of vitamins required daily. People who take vitamins pay attention to and trust the Recommended Dietary Allowances printed on vitamin bottles as a guide to what the body needs. These RDA percentages and the vitamin beliefs and practices based on them reflect a mechanistic view of the body that is in line with the prevalence of body as machine metaphors in Western society (Scheper-Hughes and Lock, 1987).

Amid concern about what they are putting into their bodies, consumers worry about the presence of bad things in their diet (e.g., processed foods and fast foods often consumed because of busy lifestyles and budget constraints). They also worry about the absence of good things (e.g., not enough fresh vegetables). In this sense, vitamin pills are perceived to correct poor food choices. They exemplify the way food consumption is conceived in terms of temporal balance. That is, in the long run, good food outweighs bad food; for example, a healthy salad for supper balances junk food at lunch. Vitamin pills help to achieve the balance.

The belief in deficiency spreads across the perceived need for individual vitamins and supplements. As people develop vitamin regimens, they focus on their own body, its deficiencies and needs, and carve out a personal system for taking care of their bodies and maintaining their health. Gary, a 46 year old law enforcement officer, started taking vitamins when he got married. His wife encouraged him to take multivitamins plus vitamins $\mathrm{C}$ and $\mathrm{E}$. After breaking his shoulder, he decided to add vitamins for joint health. Then he added flaxseed oil because his coworkers said that it is good for the eyes and brain. Adding vitamins to one's regimen is a process of self-diagnosis and trial and error. One woman we interviewed had heard from a friend that vitamin E is good for dry skin. When it seemed to help her dry skin condition, she continued taking it along with the multivitamin and vitamin $\mathrm{C}$ she had been taking. Thus, vitamins become unique to the individual and each person develops his or her own personal system.

As personal systems to replace what the body is missing, vitamin practices are creative acts of cultural production. Recent anthropological work on the concept of creativity shows how 
creativity occurs in everyday life as well as the special spheres so well articulated by Victor Turner $(1969 ; 1974)$. Rosaldo, Lavie and Narayan (1993) speak of creativity as "human activities that transform existing cultural practices in a manner that a community or certain of its members find of value" (1993:5). This definition, moving beyond the Western notion of creativity as novelty associated with individual genius, locates improvisation in social processes. We will read creative actions forward in terms of movements that give rise to them (Ingold and Hallam, 2007). Taking vitamins has become widespread in the decades since World War II. One of the movements underlying increasing vitamin consumption is the self-help movement of the 1960s and 1970s. This movement developed among citizens in relation to government. Protest against the Vietnam War and contestation of government intervention in schools opened cracks between individuals and the social body that have only widened in subsequent years. In contrast to World War II times when there was a strong sense of solidarity and connection with government, citizen protest signaled crumbling of trust in government and ushered in an age of empowerment. This expression of agency forms part of the vitamin user subjectivity. Vitamin practices are acts created apart from government and medical practice. Our forward reading of vitamin practices now turns to tactics that people pursue as they strive toward health through consumption of vitamins.

\section{SOCIAL NETWORKS AND AUTHORITY}

Vitamin practices are personal systems that involve social processes. There are several routes to feeling assured that vitamin pills are beneficial and to accepting magical thinking about their efficacy. One is tradition. Many people who currently take vitamins took them as children and belief in vitamins was passed from generation to generation as part of parental care. Barbara, a 54 year old musician and singer, has taken vitamins since childhood. Her mom gave children's multivitamins to her and her siblings. She became lax about taking multivitamins in her 20s and $30 \mathrm{~s}$ but resumed in her $40 \mathrm{~s}$ when she began to eat less meat and more vegetarian dishes. She now takes multivitamins, calcium with magnesium to prevent osteoporosis, cinnamon to regulate blood sugar levels, and turmeric as an anti-inflammatory. Tradition is a powerful symbol connecting vitamin pills to the nurturance received during childhood and lends authority to adult use. This combination of traditional knowledge and emotion is what Geertz calls common sense thought (Geertz, 1983).

Another reason for accepting vitamins and magical thinking about their efficacy is living in a managed care health care system that is consumer-directed and emphasizes agency on the part of the patient. The current economic recession in the United States plays a role in this. Some consumers are buying vitamins (e.g., vitamin $\mathrm{C}$ and echinacea) to replace prescription drugs or to treat a cold instead of going to the doctor (Williams, 2009).

Finally and perhaps most importantly, the process by which people come to put credence in the efficacy of vitamins involves family and friends. Vitamins are a socially shared competency. Men and women talk about their experience taking vitamins and share information with others in their social network. Gary, the law enforcement officer described above, added flaxseed oil to his regimen based on the recommendation of his co-workers. Vitamin users spend time learning about the purpose of different vitamins by reading vitamin bottle labels in the store, by accessing information online at manufacturer and industry websites, and by asking questions at health food stores, vitamin shops and pharmacies. As people gain a grasp of information on vitamins they 
form a knowledgeable community of users who depend on each other for guidance and validation in choosing to follow this alternative health practice.

Although health is personal, it has a social aspect that calls for external authority and approval. People who take vitamins pursue the tactic of developing social capital that includes others in a circle of family, friends and co-workers who are fellow vitamin consumers. The circle provides assurance about the efficacy of vitamin that consumers do not receive from physicians or the Federal Drug Administration (FDA). Since vitamin consumption relies on social networks and occurs outside of medical practice, it harbors a strong sense of agency resisting biomedicine and adopting an alternative health practice. Hence, health becomes defined partly in terms of the status of belonging to a community of people who assume responsibility for taking care of the body with vitamin pills.

\section{NUTRITION SCIENCE, GOVERNMENT AND PHARMA}

Nutrition science has influenced vitamin beliefs and practices by isolating individual nutrients deemed essential to body functioning. In the early part of the $20^{\text {the }}$ century scientists started to discover vitamins and minerals necessary for good health. Discovery of the link between specific vitamins and dietary deficiency diseases (e.g., C for scurvy, D for rickets, B1 for beriberi, B3 for pellagra) led to prevention of these diseases. In fact, they now occur infrequently, if at all, in the United States. This early history of vitamins and deficiency diseases set the stage for acceleration of the market that has occurred since World War II. As Apple (1996) writes in an historical account of vitamin pills in the U.S., "The cure and prevention of these rare conditions could not have sustained a multibillion dollar industry in this country. It was the sale of vitamins to apparently well-nourished middle-class consumers that supported the expansion of vitamin manufacture" (1996:85).

In post-World War II times, identification of micro-nutritional needs, nutrient by nutrient, has helped to spawn new product development in the vitamin and supplement industry and to encourage food manufacturers to include individual nutrients in processed foods. As a result, corporate marketing efforts have been oriented to informing consumers of claims to health benefits derived from taking vitamin pills as well as eating processed foods fortified with these nutrients.

Nutritional scientist Marion Nestle (2007) points out, however, that the health benefit claims of vitamin pills are statements without scientific proof because under the federal law governing the marketing of vitamins and supplements, the Dietary Supplement Health and Education Act of 1994 (DSHEA), manufacturers do not have to demonstrate that their products are safe to consume, efficacious in treating disease, or scientifically proven to provide health benefits. ${ }^{4}$ This regulatory situation provides little assurance to the public that vitamins are effective and safe. Accordingly, Nestle notes, FDA policy follows a belief-based approach to regulation rather than a science-based approach. Underlying the FDA's belief-based approach is the assumption that consumers can decide for themselves whether vitamins and supplements are worth taking. This consumer choice position actually comes from the vitamin industry and was employed in industry lobbying efforts to shape DSHEA in terms favorable to manufacturers.

The history of the relationship between government regulation and the vitamin industry reveals a piece of the subjectivity of vitamin users. DSHEA put a definitive mark on the long struggle between the FDA and pharmaceutical companies over who should judge the risks and benefits of vitamin pills. From nascent days of the vitamin marketplace and passage of the 1906 
Food and Drug Act, the FDA tried to exercise its role as protector of the health of the American people, even suggesting clinical trials for vitamin pills in the 1960s. According to Apple (1996), the tide began to turn in the 1970s when Congress first restricted the power of the FDA through the Proxmire Amendment. There have been two key issues during the almost century long debate between the FDA and industry. One is lack of scientific consensus over the efficacy and safety of vitamin pills, and the other, where to draw the line between government regulation and consumer choice. DSHEA clearly favors consumer choice, a position that consumers themselves have supported, while the issue of scientific consensus remains unresolved. At this point in time, it is fair to say that government has withdrawn substantially from regulating vitamin manufacturers, a situation which opens the door for expression of agency on the part of consumers. As Apple (1996) writes, "When scientists disagree on the need for vitamin pills, Americans do not stop believing in science. They just decide for themselves" (1996:12).

Looking at the manufacturer's health benefit claim on vitamin bottles today (e.g., 'for colon health'), one is confronted with the FDA warning, "This statement has not been evaluated by the Food and Drug Administration. This product is not intended to diagnose, treat, cure or prevent any disease." People who take vitamin pills tend to ignore this bit of government advice in the sense that they do not let it stop them and instead go on to gather and assess evidence from the pharmaceutical industry. Given the tension between government and industry, consumers pursue the tactic of seeking information from industry in order to help inform their decision-making about taking vitamins. This tactic shapes subjectivity. Disregarding government counsel and searching industry evidence are part of deciding for oneself what will work for the body.

\section{MEDICAL RESEARCH AND VITAMIN PILLS AS INSURANCE}

Excluding deficiency diseases discussed above, medical research on the role of vitamin pills in preventing disease has proven inconclusive. To date medical research does not demonstrate a correlation between vitamin use and prevention of either cancer or heart disease (Chlebowski et al., 2008; Lin et al., 2009; Nuñez-Córdoba and Martinez-Gonzales, 2011). For example, the authors of the most recent long-term study of multivitamin use conclude that although diets full of vitamin-rich foods may protect against those illnesses, the evidence does not mean that vitamin pills are a good substitute (Neuhouser et al., 2009). This is an important point that vitamin pills may not replace vitamins naturally occurring in foods. Popular food and health gurus like Michael Pollan (2006) and Wendell Berry (2009) emphasize the point to the public when recommending a diet of vitamin-rich foods in simple forms that your grandmother would recognize as food.

Despite lack of a scientifically proven connection between vitamin pills and health benefits, consumers remain committed to vitamin usage. How can we understand this behavior especially given the privileged place science holds in the Western worldview? It would seem that magical thinking is involved insofar as vitamin practices reflect thinking that is rational but not scientific. Magical thinking is based on making associations constituted by metaphor, metonymy and synchronicity. If magic involves anything alleged to exist that is not explainable by present laws of science, then vitamin pills can be said to be instruments of magic. They remain unconfirmed by an empirical cause and effect relationship. Although people may be aware that there is no definitive proof for the efficacy of vitamins, they are willing to believe that vitamins contribute to health improvement and disease prevention because of uncertainty surrounding health. The sources of this uncertainty arise at the individual level (you never know when illness will strike) 
and the social level in terms of some mistrust of the medical system (e.g., perception of doctors prescribing drugs peddled by pharmaceutical salespersons (Meier, 2011)). Such uncertainty is breeding ground for magical thinking about vitamins.

Consumers speak of vitamins as insurance to ward off potential illness. This metaphor expresses hope and doubt. Ambiguity about the effectiveness of vitamin pills surfaces when people talk about them as insurance. Tracy, a 48 year old part-time waitress and mother of two teenagers, said, "They can't hurt. They may help." If insurance provides protection against something untoward, then the metaphorical association of vitamins with insurance expresses a hopeful conviction in the efficacy of the pills. Writing in her journal, Tracy, who takes multivitamins, calcium, garlic, ginger, omega 3 and flaxseed, addressed her vitamins in the following way. "Please stay in my body and make me stay healthy." Taking vitamins is more like wearing an amulet as alternative medicine than proving something by scientific canon. As a result, uncertainty about the body having the necessary vitamin intake is replaced to some extent by uncertainty of whether vitamin pills fulfill the need. Yet there is mental and emotional satisfaction in the hope that you are giving the body what it needs, compensating for deficiencies and vices (e.g., eating unhealthy food) and keeping the body well tuned. Vitamins give people a sense of control over their bodies and wellbeing. If health is a puzzle, taking vitamins becomes part of the solution.

The relationship of consumers to medical practice and the vitamin industry speaks to subjectivity of vitamin users. The American Medical Association has been critical of the vitamin industry since its inception in the early 1900s (Apple, 1996). Physicians are typically noncommittal when talking about the effectiveness of vitamin pills with their patients even though there is recognition in the world of medical practice that many patients do take vitamins. The Physician's Desk Reference, for example, addresses interaction effects of supplements with biomedical regimens and provides advice such as not taking ginko before surgery because it acts as a blood thinner. However, consumers use the tactic of avoiding the unsupportive posture of medical practice toward vitamin pills by seeking sources of information from industry. In this sense, people grant authority to pharmaceutical companies in lieu of physicians, and it is the manufacturers who become regarded as specialists in the alternative health practice of vitamin consumption. While people do not accept information from manufacturers wholesale without assessment, assessing information provided by the pharmaceutical industry and relying on social networks involves exercise of agency.

\section{BIOMEDICINE, RESISTANCE AND AGENCY}

Taking control is a behavior that fits within the wider context of biomedicine in the $21^{\text {st }}$ century. Sociologist Nikolas Rose (2007) points out that since human life is now grasped at the molecular level, humans experience themselves in new ways as biological selves with capacity to control, manage and engineer who they are and who they want to be. Biomedicine places emphasis on self-management and self-optimization of healthy bodies. From this point of view, vitamins are self-medicating devices that become aspirational technologies of the self. Rose speaks of 'ethopolitics' which "concerns itself with the self-techniques by which human beings should judge and act upon themselves to make themselves better than they are" (2007:27). Vitamins promise the longevity and quality of life that would help consumers meet their expectations to participate fully in life (work, raise children, pursue interests, etc.). In this way vitamins refer to the morality of personhood and cultural prescriptions for the ideal person. ${ }^{5}$ 
Thus, vitamins have a complex relationship with biomedicine. On one hand, taking vitamins is supported by biomedical emphasis on individual control over the body and the biological self. On the other hand, the magical thinking involved in taking vitamins controverts the scientific thinking underlying biomedicine. Of course there is an element of art to the practice of biomedicine (Davis-Floyd ,1992; Katz, 1999). In a study on the culture of surgeons, for example, Katz describes surgeons as artists and scientists and finds that the most effective surgeons use intuition in making diagnoses and other clinical decisions. Such decisions, informed by scientific knowledge, past clinical studies and experience with patients, are based on a principle of "what works' (1999:58).

Even considering this nuanced view of biomedicine, vitamin pills are self-medicating devices that constitute an alternative health practice to biomedicine. Taking vitamins expresses the agency of taking care of one's body outside medical practice with its reliance on science and prescription medication. In addition, vitamin practices counter apprehension about the medical system. When people read or hear about problems such as pharmaceutical companies needing to withdraw unsafe drugs from the market or hospitals and doctors making mistakes in the delivery of services, they feel mistrust of the medical establishment. Although these kinds of problems may occur very infrequently, they still provide a filter for people's perceptions.

To summarize the tactics of vitamin users, people rely on social networks and assess industry information while ignoring government warning and resisting biomedicine. These expressions of agency involve action and resistance in different contexts. The social networks that are key in creating personal systems of vitamin consumption depend on the initiative of cultivating relationships and sharing experiences. The relative absence of government regulation and lack of support from medical practice provide cultural cues to seek information elsewhere. Information about the efficacy and safety of vitamin pills is sought from vitamin manufacturers, but it is accepted with a critical eye toward what might work for the individual person and what might be marketing hype to sell products. Although patients normally feel devoid of agency in the sphere of biomedicine because it is physicians with medical knowledge and technology who provide treatment, vitamin practices resist biomedical science with an alternative health modality. Thus, vitamin practices constitute not only resistance but also capacity to act and produce outcomes in the world. Resistance and action reveal how people's practices contribute to their own identities and histories (Levine, 2011). Our analysis now moves to how magical thinking fits into the subjectivity of vitamin users who define themselves as persons through a body infused with vitamin pills.

\section{MAGICAL THINKING AND THE BODY AS CAPITAL}

Magical thinking about vitamins is an expression of agency on the part of consumers. It might seem paradoxical that people who resist biomedicine with vitamin regimens can at the same time embrace the medical world. Most people do not reject doctors, hospitals and drugs when they get sick or even in pursuit of professional wellness care (e.g., annual physical checkups) and in fact often express awe over what medical technology can do. This only seems paradoxical if we consider magical and scientific modes of thought disparate. The apparent paradox harkens back to Malinowski's (1948/1954) distinction between magic and science where he notes that Trobriand Islanders engage in practical and magical thinking in relation to gardening and canoe building. He finds that these modes of thought do not seem incompatible to Trobrianders. While they know how to grow food and build canoes, they also conduct magical 
ceremonies over their crops and canoes to ward off weather that would harm their gardens and seafaring (e.g., drought, insects, gale winds). As Malinowski writes, the native knows the difference between 'science' knowledge and magic and "never relies on magic alone... But he clings to it, whenever he has to recognize the impotence of his knowledge and of his rational technique." (Malinowski 1948/1954:32). This is not to imply that magical thought is irrational for it is a rational way of knowing the world that has been opposed in anthropological discourse to a scientific way. ${ }^{6}$

Recent ethnographic work supports Malinowski's point that disjunction between magic and science is not perceived to be incompatible even in the Western context. A study of transnational Congolese traders living and working in Paris shows how successful these traders have become pursuing Western principles of business while retaining native belief in the practice of witchcraft as cause of negative events in their trading enterprise (MacGaffey and Bazenguissa-Ganga, 2000). More telling, Luhrmann's (1989) research on magic practiced in contemporary England shows that the disjunction between magic and science is not perceived to be incongruent to London magicians. Magical and scientific thinking represent different ways of knowing or different forms of human cognition. For U.S. consumers, relying on vitamins and a magical process of mind to accomplish goals for healthy living while depending on a health system dominated by scientific thinking is not a disparity. As Greenwood writes based on ethnographic study of magic in the United States, "People often blend scientific with magical thinking..." (Greenwood 2009:47).

Of course we are not suggesting that vitamin practices constitute an actual form of modern magic because there is a distinction between substantive and metaphorical magic (Luhrmann 1989). The London magicians observed by Luhrmann and those by Greenwood in the United States practice literally as they conduct rites of magic to explore and control the nonmaterial world whereas vitamin users practice metaphorically when they take vitamins to generate conditions of health and wellbeing in their bodies. Although belief in the efficacy of vitamins is not necessarily based on false premises as Frazer (1922) might have argued, neither are the premises confirmed by science. Magical and scientific modes of thought or orientations to the world are intertwined in human thought processes (Tambiah, 1990). As Tambiah writes, "Analytically separate, they are intertwined in many mixes..." (1990:110) and "...although societies and cultures do differ in the variety of discourses they permit and encourage, certainly no society hitherto known is an impoverished practitioner of only a single orientation" (1990:108-109).

Using a magical mode of thought, people who take vitamin pills actively engage in imagining a connection between mind and body. The connection is envisioned as communication from the body to the person. If consumers skip their vitamins for a day or two or more, they claim that their body tells them that they are missing their vitamins because they feel tired and lack pep. For example, Gail, a 52 year old high school teacher, says that when she's rushing out the door and forgets to take her vitamins for a few days she feels more tired than usual. Further, consumers use the associative thinking of magic to imagine how vitamin pills work in their bodies. One female respondent described how she could feel calcium coursing through her blood stream and adding layers of strength to her bones. A male respondent talked about being aware of vitamin $\mathrm{C}$ fighting off germs that were attacking his body and causing cold symptoms. These imaginings play out Frazer's notion of sympathetic magic as the association of ideas by similarity or contact (Frazer, 1922). With magical thinking about vitamins, there is transfer of power through contact. People claim a transfer of power from vitamin pill to the body when they 
say that they feel effects immediately even though digestion of the pill may take 12-15 hours and absorption into body cells even longer. Magical thinking about vitamins also invokes a transfer of power through metonymy when a vitamin capsule is felt to provide the benefit of the whole nutrient source (e.g., garlic capsule that condenses the whole garlic bulb or a saw palmetto capsule that equals the whole desert plant). In a magical mode of thought, health becomes embodied through imagination and emotion. As Greenwood writes, magical consciousness is “... an affective awareness experienced through an alternative mode of mind" (Greenwood 2009:63). These sensory imaginings about vitamins reflect recent work in anthropology that provides a new post-Malinowskian interpretation of magic in terms of the senses (Novellino, 2009; Classen, 2005). The potency of vitamins as a health giving force is perceived through the sensory modalities of the body and permeated with social values. Based on research in psychology on embodied cognition (Jostmann et al., 2009; Miles et al., 2010) and mind-powered healing (Langer, 2009), the idea that abstract thoughts and feelings can be taken literally by the body supports this sensory interpretation of magic and magical thinking. People who claim that vitamins make them feel better may actually feel better because the mind can condition the body. In effect, taking vitamins is an expression of agency that resists biomedicine's rootedness in the duality of mind and body.

Vitamin practices reveal symbolic capital invested in the body. They enact two theoretical orientations toward the body, the body as object or symbol expressing social values, and the body as subject or agent creating social meaning (Reischer and Koo, 2004). As object, the body is site of symbolic representation of the social world it inhabits (Douglas, 1970). Vitamin practices reflect the body as object because social meanings about health are inscribed on it. The body becomes a vessel through which people make decisions about healthy living. John, a 40 year old businessman, includes glucosamine and chondroitin in his vitamin regimen to keep his knee joints pain free and resilient for long-distance running. He runs for fitness, weight control and muscle tone, to maintain a healthy body, and to enhance presentation of the self to the world. $\mathrm{He}$ is conscious of how his body looks to himself and to others. Taking vitamins and running make him feel good about himself. Through vitamin practices people convey meaning about identity and social relations and express cultural dimensions of health such as fitness, appearance and wellbeing. Of course the meaning of health as self-presentation (looking good as well as feeling good) is accentuated for women because they live with cultural prescriptions that lead them to perceive and internalize body functionality in terms of health and beauty. This demonstrates how the body is an object or symbolic field for the reproduction of dominant values and the exertion of power and social control (Reischer and Koo, 2004). In addition to object, the body also serves as subject actively participating in the creation of social meaning that in the case of vitamins involves personhood.

\section{VITAMINS, ENERGY AND CONSTRUCTING PERSONHOOD}

When people take vitamin pills, the body becomes a site for constructing personhood. Since the Enlightenment the configuration of person in Western society has emerged from individualism and property. According to Strathern (1999), a recent shift has occurred in demarcating human effort over nature from property to technology. Strathern writes that EuroAmericans so ardently embrace technology that it affects the way we think about "persons and things alike as actants" (1999:24). Looking at the body as subject shows how the person has 
capacity to act in the world and transform systems of meaning. It is through the body infused with vitamins and thereby commodified that consumers define themselves as persons.

Vitamins incorporate the technology of production with the aspirational technology of the self. That is, taking manufactured vitamins provides means to create the person you want to become. The key symbol of vitamins is energy. People who take vitamins speak of feeling energized by them. Metaphors they use to describe this energized state refer to production and orientation of the self to the world. Roberta, a nurse in her 50s with college age children, said that vitamins make her feel like a rooster because she wakes up in the morning feeling healthy, full of energy, stronger and more productive than if she weren't taking vitamins. She also used the metaphor of a clown meaning that vitamins make her feel vivacious and give her a positive attitude toward life. These metaphors reflect the way consumers think about energy and personhood, and the metaphors structure experience of the body (Lakoff and Johnson, 1980). Vitamin takers say that they can feel the effect of taking vitamins making them less sluggish and more peppy. Vitamins are believed to generate energy literally and metaphorically. They are experienced physically in terms of providing strength and vitality to the body and emotionally in the sense of making the person feel confident, goal-oriented and ready to take on the world. Vitamins refashion body and mind.

The energy metaphor carries particular meaning for personhood in capitalist society where energy is prized as a source of innovation and change. Martin (2007) addresses this notion of energy in personhood through a study of manic depression in the United States. Looking at the social context of manic depressive behavior, Martin finds that part of manic depression, the mania, has a positive gloss. It is paired with almost anything or activity that people greatly desire, and it indicates creativity and creative contributions to society in many fields such as business and entertainment. For Martin, mania reflects unfettered capitalism in contemporary American culture because it implies a person perceived to be creative, hyper-energized and fearless in the face of competition. Vitamins can be cast in a similar interpretive frame because they refer to the energy of human enterprise celebrated in the American Dream with narratives of the industrious person who succeeds through hard work. Vitamins embody the productivity inherent in capitalism and the emphasis in consumer culture on doing (Belk 1988), self-creation (Sunderland and Denny, 2007) and life as a process of becoming (McCabe and Malefyt, 2010). By taking vitamins individuals experience themselves as healthy, energetic and productive persons who are improving the self, achieving personal goals and doing something positive in the world. This construction of personhood draws on the notion of progress that has been integral to cultural images of society in the United States. ${ }^{7}$ Activity, creativity and performance imply continuously moving forward and getting better individually and collectively.

The association of energy with capitalism is rooted in Puritanism and distinguishes the contemporary West from other historical times and places (Weber, 1958). Calvinist ideas connecting asceticism to the productive body and worldly success as a sign of salvation differ, for instance, from notions of energy in early medicine. In traditional medical systems, energy refers to balance between the body and the environment (Chen, 2009). In ancient Chinese practice, energy known as $q i$ was thought to flow through humans, plants, animals and physical spaces and, as Chen writes, "Combinations of foods with different properties could promote or restore balance in a person's health" (2009:23). This orientation of energy in relation to the body and the environment is quite different from the notion of energy as productivity that developed with capitalism in the $18^{\text {th }}$ and $19^{\text {th }}$ centuries. Vitamins embody capitalism by evoking ideas of energy, productivity and self-creation in the definition of personhood. 


\section{VITAMIN RITUALS AND WHOLENESS}

Daily vitamin rituals give people an experience of being whole persons that the Western way of thinking in terms of dichotomies does not provide. Key dimensions to this experience of wholeness include the joining of mind and body, individual and society, and nature and society. Anthropologists have become aware of the ethnocentrism in using these kinds of dichotomies as analytic concepts and have argued in favor of moving beyond them (Appadurai, 1986; SchepherHughes and Lock, 1987), but the point we wish to make is that the dualism pervasive in Western thought affects everyday lives. Vitamin practices let people experience and enjoy connection between domains that have been discrete, even opposite, in the Western worldview. In this sense they are creative acts that transform structure and form part of a new subjectivity.

\section{Mind and Body}

Vitamin rituals overcome the split between mind and body in biomedicine and Western thought generally with a sense of wholeness. Medical anthropology has called attention to fragmentation of the body in biomedicine and the embodiment of social injustice in disease and in health care (Martin, 1987; Schepher-Hughes, 2004; Farmer, 2005). What this work suggests is a conceptual lack of the whole person underlying medical relationships and practices. Because of the mind-body duality, biomedicine and biotechnology find value not in the whole body but in fragmented body parts (Lock and Scheper-Hughes, 1990; Strathern, 2004; Everett, 2007). Vitamin manufacturers participate in fragmenting the body by problematizing specific body parts and processes for which vitamin pills are made (e.g., heart, bones, joints, prostate, immune system, menopause, tension). While vitamins replicate fragmentation of the body, they also promise a holistic approach to health. If emphasis on the fragmented body suggests something negative about personhood (body divorced from mind), the narrative of vitamin practices indicates something positive, namely integration of mind and body.

People speak of their vitamin rituals in terms of connecting mind and body. They say that at the moment of taking vitamins, you know you're doing something good for yourself. This brings together the senses, emotions, and conscious awareness. Sandra, a stay-at-home mom with children 9 and 14 years old, describes the ritual affect as calming, centering and quieting. She says that it is like holding a yoga pose, thinking about different parts of your body and breathing into them. Knowledge about vitamins in concert with actually taking the pills brings about a state of harmony where people enjoy a heightened sense of awareness and enhanced overall wellbeing. Here we want to differentiate wellbeing from wellness, concepts used in different contexts. Compared to the concept of wellness which comes from the health field and means being disease free and engaging in preventive medicine practices, wellbeing is a more psychosocial concept that connotes feeling good about the self, fully alive, in tune body and mind with an awareness of self that may even include a spiritual dimension. We know from Myers' (1979) seminal study on emotions among Australian Aborigines that personhood reflects a moral order, and the sense of wellbeing derived from vitamin rituals refers to morality and character. It confirms the vitamin user as a whole person whose energy can be used creatively and productively.

Ritual aspects of vitamin practices involve where to keep vitamins, how to take them, and when it is best to take them. These factors are believed to affect the ability of vitamins to produce the desired result of feeling energetic, whole and healthy. People keep vitamins in a special place (e.g., kitchen counter, or middle of the table, in plain sight where they serve as a 
reminder) and take them at the same time everyday usually with the same beverage. The moment of consumption makes the person more fully present to self than at other times during the day. Perceptions of joining mind and body in the act of consuming vitamins revitalizes the whole person with a sense of readiness to accomplish everyday life things like chores in the home or tasks in the workplace. Vitamin rituals are a locus where magical thinking and the resulting integration of mind and body are experienced.

\section{Individual and Society}

Vitamin practices are personal systems embedded in social relations. Evans-Pritchard's work among the Azande shows that patterns of magic and witchcraft arise from the social body and can generate, maintain and disrupt the social order (Evans-Pritchard, 1937). As a social process challenging biomedicine, vitamin practices depend on sources of authority outside the medical system to legitimize and support use. People who take vitamins rely on input and assurance from social circles and other sources of information including vitamin manufacturers. These connections give the individual a sense of belonging to larger social groups.

Vitamin practices highlight re-conceptualization of personhood in Western society as a combination of individuality and sociality. Early ideas about personhood, a perennial topic in anthropological theory, compared Western conceptions of personhood to either Eastern constructions or so-called primitive notions. This perspective was influenced by Mauss' essay $(1938 / 1950)$ in which he indicates that personhood varies by time and place and argues from an evolutionary point of view that earlier societies had a more sociocentric concept of the person based on kinship than modern Western societies where the idea of person emanates from individualism. While his premise that personhood is contextualized across time and space has been validated repeatedly by ethnographic work, contemporary scholars have been critical of the emphasis, over-emphasis if you will, on individualism in the portrayal of personhood in modernity. Douglas and Ney (1998), for example, in a treatise against the rational and isolated entity homo economicus, describe everyone as an ensemble of social relations. Willerslev (2007) also argues that personhood entails relationships and adds that anthropology has suffered from Cartesian dualisms underlying Durkheimian approaches to understanding behavior (e.g., the duality of individual and group). Vitamin rituals express integration of individual and society because they are oriented to the needs of individuals but performed within a community of users joined in seeking an alternative health modality.

\section{Nature and Society}

Vitamins are considered a private matter regulated by the individual according to his or her body and health needs. They are even autobiographical in that people can mark time and life segments by describing vitamin usage (e.g., during pregnancy, beginning of heart trouble, onset of diabetes). However, vitamins are enmeshed in broader discourses including medicalization of the body (Martin, 1990) and marketing of health related products (Baer, Singer and Susser, 2003). By focusing on vitamin pills as natural substance yet technological feat, these wider parameters of discourse bring a sense of wholeness combining nature and society into vitamin practices.

The existence of social movements that consider the body a 'fence' between individual and public interests shows that the body and health are historically places for conflict. Not In My Body (NIMB), for instance, a contemporary movement that takes the body as a symbol of tension between the individual and social politics, opposes everything that is produced and 
marketed without having the health and care of the individual as the main objective (DuPuis, 2002). Hence, the body is perceived responsible for protecting boundaries against the external world and for maintaining internal balance. Movements like NIMB calling for a return to nature with simpler, unprocessed, and uncontaminated foods reflect the duality in the Western worldview between nature and society. In the case of vitamin pills, society features biomedicine and industrialized food while nature presents 'natural nutrients' and a community of users who share knowledge about those nutrients and common ground for resisting the dominant medical system.

Vitamins stand at the crossroad of two seemingly opposite discourses and practices, namely hyper-medicalization and return to nature. Because they are 'soft medicines' not requiring physician involvement, vitamins are perceived to belong to a natural environment where health can be maintained at home. They exist more in the realm of nature than the science of biomedicine. Knowledge and influence stem from supportive social circles rather than sterile laboratory environments. In U.S. cultural logic, natural is better. On the other hand, the continuing development of new products in the vitamin industry, often appropriating knowledge and medicines from traditional medical systems, communicates to consumers the wonders of a modern technology that can produce vitamin pills claiming health benefits. Such pills retain appeal in a cultural landscape of techo-fixes. The technocratic imperative in the United States is an ideology based on belief in the ultimate power of technology to solve problems (Davis-Floyd, 1992).

Connection to what is perceived natural gives vitamins special status as superior foodstuff, almost from the gods, because they provide not only physical nutrients but also emotional benefits like companion spirits. Vitamins are a missing link in knowing that you are replenishing what the body does not get from foods, especially 'unnatural' processed foods and poor diets, and in realizing that you are taking care of your body and your health for yourself and for the sake of loved ones. Since vitamins are assumed to be pure and safe despite limited FDA governance, there is promise of achieving balance with a natural food. Balance is natural in that it results from the individual staying in control, coordinating different forces that affect health, and insuring the wellbeing of self and society. Taking vitamins expresses a philosophy of life embraced as a positive health value at almost all layers of society.

In marketing and advertising, positive images of health are associated with people who take vitamins. Advertisements show a diversity of people in many sizes and forms (male, female, children, young adults, the elderly). They appear smiling, energized, satisfied and accomplished. Even animals are portrayed active and happy as if health were a universal gift from vitamin pills. These images radiate success because ability to maintain health is perceived to be part of human advancement, a morality play put into action. Vitamins are seen as instruments of technological progress, like nature, only more perfect. They enjoy the status of perfected food by combining the symbolic weight of basic and natural with hyper-modern and sophisticated. In this way, vitamin rituals bring into harmony the experience of nature and society.

\section{CRITICAL PERSPECTIVE: SEEKING HEALTH, PROMISING HEALTH}

Vitamin pills embody the knowledge, discourse and power of manufacturers. Since its inception in the early 1900 s, the vitamin industry has spent millions trying to convince the public of its need for vitamin pills (Apple, 1996). For pharmaceutical companies, the human body has become a site for the promise of health and the reaping of profit. In light of the scientifically 
unproven efficacy of vitamin pills, how has the discourse and power of manufacturers tried to sway people, and how do people in their quest for health assess information from industry? In other words, how is agency configured in the relation between consumer and manufacturer?

The vitamin industry has employed science as an ideology of power (Foucault, 1980). It continues to introduce new products that increasingly mimic plants from indigenous pharmacopoeia and at the same time it speaks of scientific evidence backing these products. Manufacturing companies typically test for efficacy and safety of vitamin pills through in-house research and commissioned studies and not through clinical trials. This may lead to the corporate conspiracy, government collusion, and hegemonic interaction between producers and consumers that exists in the pharmaceutical industry (Singer and Baer, 2009). Corporate conspiracy occurs when companies hide information about the risk of products in order to earn profits. Due to the industry favorable regulatory structure of DSHEA, vitamin manufacturers are not required to prove the efficacy and safety of products through clinical trials. Whether vitamins and supplements are effective and safe, or at least not harmful, is not known to the public. Nestle writes, "From a scientific perspective, the preponderance of available evidence suggests that if they were tested, the great majority of supplements now on the market would prove to be no more effective than placebos and that a few would be demonstrably harmful" (2007:231). There is government collusion regarding absence of science in vitamin regulation. A revolving door between industry and regulatory bodies allows people to move back and forth between positions in manufacturing and the FDA and FTC (Nestle 2007). Hence, criticism of industry's use of the language of science as a tool of persuasion remains unchecked. Hegemonic interaction arises from industry communications based on cultural ideas about science that equate health with images of being active and happy. Such marketing and advertising constitutes 'affect management' (Mazzarella, 2003:35). People who take vitamins participate in hegemonic interaction by responding to industry media with magical thinking about the efficacy of vitamin pills and imagining the energy and wholeness they bring to the body. Concerned over what they put into their bodies, people see vitamin pills as a purer and safer means to satisfy nutrient deficiencies than food from an industrialized farming system. Independent reports questioning need for specific vitamins, such as the recent review of vitamin D and calcium in relation to osteoporosis, do not seem to halt increase in reported sales (Kolata, 2010).

People choose vitamin pills to extend the boundary around what the body can do - for example, manage pregnancy, overcome diabetes, run a marathon or deal with growing older. As vitamin regimens evolve and change over time in response to such transitional moments in life, figuring out what the body needs evokes excitement like concocting a new recipe to become healthier. Although vitamin pills may lack scientific proof, people rely on other modes of cognition including magical thinking, common sense thought and sensory knowledge to judge whether they are working in the body. This situation means agency resides partly inside the person because people know on the basis of these other ways of knowing yet manufacturers retain power by speaking convincingly as if products enjoy confirmation through the scientific method.

\section{VITAMINS AND THE POLITICAL ECONOMY}

As a social practice embedded in the political economy, vitamins have two entwined but divergent effects in society. On one hand, vitamins create a leveling effect because they are available to everyone. This is true at least of those distributed at lower price points. They become 
a democratizing force in society. Entry to the health benefits claimed by manufacturers is open. On the other hand, vitamins act as a hierarchical force because of differential access by socioeconomic status to higher priced products. Proliferation of products at higher price points closes access to vitamins and health benefits they claim to provide. Purchase and consumption of more costly vitamin brands, arguably better in terms of quality, become badges of honor and signs of distinction (Bourdieu, 1984). When expensive bottles of vitamin pills stand in a public place in the home, they signify a more elite access to health for members of the household.

Vitamins are a form of body politic. In the case of pharmaceutical drugs, the notion of the individual as proprietor of the self gives way to the idea of the person living within social constraints (Wendel and Hardy, 2006). This shift occurs because the body belongs to a person with a lifestyle and socioeconomic standing that affects how one understands, uses and experiences a medication. The same argument applies to vitamins. Consumers are part of the politics of a market that supports a plethora of products with differences even within the same type of vitamin. There are synthetic and plant-based vitamins, pills combining two or more ingredients, variations in strength, varieties of form (pill, gel capsule, liquid), and different brands. Such product differences translate into cost on the shelf. People who buy more expensive products (e.g., organic vitamins) believe they provide better quality with greater power to create a healthier body. Thus, more expensive vitamins erase the equality assumed in the democratic scenario by reproducing economic and social inequality. The pharmaceutical industry operates different markets in rich versus poor countries based on the culture of users, their economic characteristics and potential to enhance industry profits (Petryna and Kleinman, 2007), and vitamin manufacturers maintain distinct markets in the United States for the same reasons.

\section{CONCLUSIONS}

Vitamin practices reveal a subjectivity that has developed since World War II with the growth of a vitamin marketplace. This subjectivity centers on taking responsibility for health in a way that did not previously exist, so the emergence of vitamin practices provides a way to explore social change. Tactics pursued by vitamin users show how the agency of operating within a field of wider social processes is transformative. Vitamin practices have changed the structure of health care. Where care of the body had been more relegated to the domain of physicians and the realm of biomedicine supporting medical practice, vitamin practices partially transferred care of the body to individuals and their reliance on social networks. The increasing rate of vitamin use in the United States reflects a subjectivity that resists biomedicine and adopts an alternative health practice. Included in this subjectivity is a construction of personhood that expresses the agency of developing the body and the self as an energetic, productive and creative person in capitalist society. This involves the work of the imagination operating outside the dominant medical system and envisioning the body in terms of wholeness.

We have argued that the concept of tactics provides theoretical means to understand the agency of actors within the structure of society (de Certeau, 1984). It focuses attention on building cultural capital to the advantage of the individual and on the strategic nature of social exchanges (Moeran, 2005). Agency involves not only the set of dispositions ascribed to practice (Bourdieu, 1977), but also actions oriented to achieving goals. People who take vitamin pills resist biomedicine and act according to their own definitions and experience of health and wellbeing. Although individuals make decisions and shape the social world in which they live, they are constrained by broader social, political and economic forces. The agency of vitamin 
users is limited by the pharmaceutical industry which retains power with an ideology of science and maintains a marketplace that sets up inequalities with products of differing quality and price. While people who take vitamins ally themselves with manufacturers, they also rely on personal knowledge of what works for them and those in their social networks. Ideology can be dominant (Foucault 1980) though not necessarily totalizing. As a result, agency can be seen as a nuanced concept depending on context or frame. In the biomedical frame, the patient's agency is limited in deference to physicians. In the social frame of family and friends, agency is robust as the individual initiates and operates within a community of vitamin users. In the pharma frame, the locus of power resides in part with the person assessing information about vitamins and partly with manufacturers who do not provide, and are not required under federal statute to provide, scientific proof of the efficacy and safety of vitamin pills. Thus, the concept of tactics pursued in different contexts puts the relationship between agency and structure in a more dialectical perspective.

Current expansion of the vitamin and supplement market occurs with the rise of what Giddens calls the reflexive modern self where "the self, like the broader institutional contexts in which it exists, has to be reflexively made" (1991:3). This reflexivity extends to the body since we know ourselves and the world through our bodies. For Giddens, humans have become more reflexive because the surety of tradition is replaced not by the certitude of rational thought but by a diversity of authorities. People making decisions about health and vitamins encounter the authority of other knowledgeable consumers in their social networks, the authority of specialists representing the vitamin industry, and the authority of physicians (even if they remain noncommittal about the merits of taking vitamins). The process of evaluating information about vitamins brings to light the doubt that Giddens ascribes to the reflexive modern self. Doubt emerges in the blending of different modes of thought. While vitamins address the uncertainty of health, they leave people with the irony of believing in the efficacy of vitamin pills (through magical thinking, common sense thought, and sensory knowledge) yet not knowing whether they are effective (based on scientific thinking). Our analysis of tactics as a bridge between agency and structure gives access to this doubt as a dimension of the subjectivity of vitamin users. Different ways of knowing cohere in the modern reflexive self.

\section{ACKNOWLEDGEMENTS}

The authors wish to thank Timothy deWaal Malefyt for useful comments on a previous draft of this article. The lead author also wishes to thank Marie Lemerise of Rethink for collaboration on one of the market research projects on which this article is based.

\section{NOTES}

1. Cited at www.nnfa.org, accessed March 4, 2009.

2. Comparative sales figures in the vitamin and supplement industry are difficult to obtain. Nutrition Business Journal, a market research firm that provides analyses of the nutrition business, issues a report with sales figures every two years. The 2010 report costs $\$ 2,995$ but an executive summary is provided free online. According to this executive summary, 2008 global nutrition industry sales were \$270 billion including \$27 billion in the United States. Apple (1996) gives a sense of the rising sales in the United States: \$12 million in 1931, \$83 million in 1939, \$131 million in 1942, \$1 billion in 1980, and \$4 billion in 1994. 
3. We use the term 'vitamins' to include vitamins and supplements. We refer to the entities sold commercially, typically in bottles, containing synthetic or plant-based vitamin and supplement pills. This follows conventional language use. People speak of taking their vitamins when they take vitamins and supplements, and in the retail environment there are vitamin aisles and vitamin stores that sell both vitamins and supplements.

4. Regulation of the vitamin and supplement industry under DSHEA is complex. There are two federal agencies involved, the Food and Drug Administration (FDA) and the Federal Trade Commission (FTC). The FDA is concerned with product safety and accurate product labeling, the FTC with promoting business competition and preventing false advertising. Regulatory standards and practices are so lame that one can say the vitamin and supplement industry is unregulated (Nestle 2007).

5. Recent scholars concerned with construction of human subjectivity address issues relating to self, identity and person in anthropological thinking (Desjarlais 1999, Whittaker 1992). The concept of personhood has long been associated with the emotions and morality (Myers 1979). For Myers, personhood reflects a moral order which in Geertzian terms implies a model of and a model for how one should think, feel and behave (Geertz 1973).

6. Magic is a discursive topic practically synonymous with anthropology since the earliest days of fieldwork. Malinowski's (1948/1954) distinctions between magic, science and religion and Evans-Pritchard's (1937) discussion of belief and witchcraft set off a famous rationality debate in anthropology and philosophy; for example, see Gellner (1992). This debate has been chronicled most recently in Luhrmann (1989) and Greenwood (2009).

7. The notion of progress in Western thought is an Enlightenment idea associated with science and the theory of evolution. In recent times, social scientists have endeavored to eliminate this notion from discourse because evolution does not necessarily imply progress of human society over time. Stephen Jay Gould's writings have brought this point home to cultural anthropologists; for example, see Gould (1980).

\section{REFERENCES}

Ahearn, L.A. (2001). Language and Agency. Annual Review of Anthropology 30, 109-137.

Appadurai, A. (1986). Introduction. In The Social Life of Things: Commodities in Cultural Perspective. ed. A. Appadurai. Cambridge: Cambridge University Press.

Apple, R.D. (1996). Vitamania. New Brunswick, NJ: Rutgers University Press.

Baer, H.A., Singer, M. and Susser, I. (2003). Medical Anthropology and the World System. Westport, CT: Praeger Publishers.

Belk, R. (1988). Possessions and the Extended Self. Journal of Consumer Research 15, 139-168.

Berry, W. (2009). Bringing It to the Table: On Farming and Food. Berkeley: Counterpoint.

Bourdieu, P. (1977). Outline of A Theory of Practice. Cambridge: Cambridge University Press. 
Bourdieu, P. (1984). Distinction: A Social Critique of the Judgment of Taste. Cambridge: Harvard University Press.

Chen, N.N. (2009). Food, Medicine, and the Quest for Good Health. New York: Columbia University Press.

Chlebowski, R.T. et al. (2008). Calcium plus Vitamin D Supplementation and the Risk of Breast Cancer. Journal of the National Cancer Institute 100 (22), 1581-91.

Classen, C. (2005). The Witch's Senses: Sensory Ideologies and Transgressive Femininities from the Renaissance to Modernity. In Empire of the Senses: The Sensual Culture Reader, ed. D. Howes. Oxford: Berg.

Davis-Floyd, R.E. (1992). Birth as an American Rite of Passage. Berkeley: University of California Press.

de Certeau, M. (1984). The Practice of Everyday Life, trans. S. Rendall. Berkeley: University of California Press.

Desjarlais, R. (1999). The Makings of Personhood in a Shelter for People Considered Homeless and Mentally Ill. Ethos 27, (4), 466-489.

Douglas, M. (1970). Natural Symbols: Explorations in Cosmology. London: Barrie and Jenkins, Cresset Press.

Douglas, M. and Ney, S. (1998). Missing Persons: A Critique of Personhood in the Social Sciences. Berkeley: University of California Press.

DuPuis, E.M. (2002). Nature's Perfect Food: How Milk Became America's Drink. New York: New York University Press.

Evans-Pritchard, E.E. (1937). Witchcraft, Oracles and Magic Among the Azande. Oxford: Clarendon Press.

Everett, M. (2007). The "I" in the Gene: Divided Property, Fragmented Personhood, and the Making of a Genetic Privacy Law. American Ethnologist 34, (2), 375-386.

Farmer, P. (2003). Pathologies of Power: Health, Human Rights, and the New War on the Poor. Berkeley: University of California Press.

Foucault, M. (1980). Power/Knowledge: Selected Interviews and Other Writings, 1972-1977, ed. C. Gordon. New York: Pantheon Books.

Frazer, Sir J.G. (1922). The Golden Bough: A Study in Magic and Religion ${ }_{2}$ abridged ed. New York: Macmillan. 
Geertz, C. (1973). Religion as a Cultural System. In The Interpretation of Cultures. New York: Basic Books.

Geertz, C. (1983). Common Sense as a Cultural System. In Local Knowledge: Further Essays in Interpretive Anthropology. New York: Basic Books.

Gellner, E. (1992). Reason and Culture: The Historical Role of Rationality and Rationalism. Oxford: Blackwell.

Giddens, A. (1979). Central Problems in Social Theory: Action, Structure and Contradiction in Social Analysis. Berkeley: University of California Press.

Giddens, A. (1991). Modernity and Self-Identity: Self and Society in the Late Modern Age. Stanford: Stanford University Press.

Gould, S.J. (1980). The Panda's Thumb. New York: Norton.

Greenwood, S. (2009). The Anthropology of Magic. Oxford: Berg.

Ingold, T. and Hallam, E. (2007). Creativity and Cultural Improvisation: An Introduction. In Creativity and Cultural Improvisation. ed. E. Hallam and T. Ingold. Oxford: Berg.

Jostmann, N.B., Lakens, D. and Schubert, T.W.. Weight as an Embodiment of Importance. Psychological Science 20, 1169-1174.

Katz, P. (1999). The Scalpel's Edge: The Culture of Surgeons. Boston: Allyn and Bacon.

Krause, E.L. (2009). Unraveled: A Weaver's Tale of Life Gone Modern. Berkeley: University of California Press.

Lakoff, G. and Johnson, M. (1980). Metaphors We Live By. Chicago: University of Chicago Press.

Langer, E.J. (2009). Counterclockwise: Mindful Health and the Power of Possibility. New York: Random House.

Levine, M.N. (2011). Negotiating Political Economy at Late Postclassic Tututepec (Yucu Dzaa), Oaxaca, Mexico. American Anthropologist 113, (1), 22-39.

Lin, J. et al. (2009). Vitamins C and E and Beta Carotene Supplementation and Cancer Risk in a Randomized Controlled Trial. Journal of the National Cancer Institute_101, (1), 14-23.

Lock, M. and Scheper-Hughes, N. (1990). A Critical-Interpretive Approach in Medical Anthropology: Rituals and Routines of Discipline and Dissent. In Handbook of Medical Anthropology: Contemporary Theory and Method. ed. T.M. Johnson and C.F. Sargent. Westport, CT: Praeger. 
Luhrmann, T.M. (1989). Persuasions of the Witch's Craft: Ritual Magic in Contemporary England. Cambridge, MA: Harvard University Press.

Malinkowski, B. (1948/1954). Magic, Science and Religion and Other Essays. Garden City, NY: Doubleday.

Martin, E. (1987). The Woman in the Body: A Cultural Analysis of Reproduction. Boston: Beacon Press.

Martin, E. (1990). Toward an Anthropology of Immunology: the Body as Nation State. Medical Anthropology Quarterly 4, 410-426.

Martin, E. (2007). Bipolar Expeditions: Mania and Depression in American Culture. Princeton: Princeton University Press.

Mauss, M. (1938/1950). Une Catgegorie de 'Espirit Humain, trans. W.D. Halls. In The Category of the Person: Anthropology, Philosophy, History. ed. M. Carrithers, S. Collins and S. Lukes. Cambridge: Cambridge University Press.

MacGaffey, J. and Bazenguissa-Ganga, R. (2000). Congo-Paris: Transnational Traders on the Margins of the Law. Bloomington: Indiana University Press.

Mazzarella, W. (2003). 'Very Bombay': Contending with the Global in an Indian Advertising Agency. Cultural Anthropology 18, (1), 33-71.

McCabe, M. and Malefyt, T. (2010). Brands, Interactivity and Contested Fields: Exploring Production and Consumption in Cadillac and Infiniti Automobile Advertising Campaigns. Human Organization 69, (3), 252-262.

Meier, B. (2011). Tipping the Odds for an Implant Maker: Paying Doctors, A Supplier Succeeds in Las Vegas. The New York Times, National, April 3, (1), 17.

Metzl, J.M. (2010). Introduction: Why against Health? In Against Health: How Health Became the New Morality. ed. J.M. Metzl and A. Kirkland. New York: New York University Press.

Miles, L.K., Nind, L.K. and Macrae, C.N. (2010). Moving through Time. Psychological Science $21,1-2$.

Moeran, B. (2005). The Business of Ethnography: Strategic Exchanges, People and Organizations. Oxford: Berg.

Moeran, B. (2011). Perspectives in Business Anthropology: Cultural Production, Creativity and Constraints. International Journal of Business Anthropology 2, (1), 16-30. 
Myers, F.R. (1979). Emotions and the Self: A Theory of Personhood and Political Order among Pintupi Aborigines. Ethos 7, (4), 343-370.

Nestle, M. (2007). Food Politics: How the Food Industry Influences Nutrition and Health. Berkeley: University of California Press.

Neuhouser, M.L. et al. (2009). Multivitamin Use and Risk of Cancer and Cardiovascular Disease in the Women's Health Initiative Cohorts. Archives of Internal Medicine 169, (3), 294-304.

Novellino, D. (2009). From 'Impregnation' to 'Attunement': A Sensory View of How Magic Works. Journal of the Royal Anthropological Institute 15, (4), 755-776.

Nutrition Business Journal. (2010). NBJ's Global Supplement and Nutrition Industry Report 2010: An Analysis of Markets, Trends, Competition and Strategy in the Global Nutrition Industry. New York: Penton Media.

Nuñez-Córdoba, J.M. and Martinez-González, M.A. (2011). Antioxidant Vitamins and Cardiovascular Disease. Current Topics in Medicinal Chemistry, April 21.

Ortner, S.B. 1984. Theory in Anthropology since the Sixties. Comparative Studies in Society and History 26, (1), 126-166.

Pollan, M. (2006). The Omnivore's Dilemma: A Natural History of Four Meals. New York: Penguin Books.

Reischer, E. and Koo, K.S. (2004). The Body Beautiful: Symbolism and Agency in the Social World. Annual Review of Anthropology 33, 297-317.

Rosaldo, R., Lavie, S. and Narayan, K. (1993). Introduction: Creativity in Anthropology. In Creativity/Anthropology. ed. S. Lavie, K. Narayan and R. Rosaldo. Ithaca: Cornell University Press.

Rose, N. (2007). The Politics of Life Itself: Biomedicine, Power, and Subjectivity in the TwentyFirst Century. Princeton: Princeton University Press.

Scheper-Hughes, N. (2004). The Last Commodity: Post-Human Ethics and the Global Traffic in 'Fresh' Organs. In Global Assemblages: Technology, Politics, and Ethics as Anthropological Problems. ed. A. Ong and S. Collier. London: Basil Blackwell.

Scheper-Hughes, N. and Lock, M. (1987). The Mindful Body: A Prolegomenon to Future Work in Medical Anthropology. Medical Anthropology Quarterly 1, (1), 6-41.

Singer, M. and Baer, H. (2009). Killer Commodities: Public Health and the Corporate Production of Harm. Lanham, MD: Alta Mira Press. 
Strathern, M. (1999). Property, Substance and Effect: Anthropological Essays on Persons and Things. London: Athlone

Strathern, M. (2004). The Whole Person and Its Artifacts. Annual Review of Anthropology 33, 119.

Sunderland, P.L. and Denny, R.M. (2007). Doing Anthropology in Consumer Research. Walnut Creek, CA: Left Coast Press.

Tambiah, S.J. (1990). Magic, Science, Religion, and the Scope of Rationality. Cambridge: Cambridge University Press.

Turner, V. (1969). The Ritual Process. Chicago: Aldine.

Turner, V. (1974). Dramas, Fields, and Metaphors. Ithaca: Cornell University Press.

Weber, M. (1958). The Protestant Ethic and the Spirit of Capitalism. trans. T. Parsons. New York: Charles Scribner's Sons.

Wendel, J.P. and Hardy, L.J. (2006). Transitions/Translations/Gaps: Ethnographic Representations in the Pharmaceutical Industry. Social Transitions 1, 160-165.

Whittaker, E. (1992). The Birth of the Anthropological Self and Its Career. Ethos 20, (2), 191219.

Willerslev, R. (2007). Soul Hunters: Hunting, Animism and Personhood among the Siberian Yukaghers. Berkeley: University of California Press.

Williams, A. (2009). As Economy Is Down, Vitamin Sales Are Up. The New York Times, National, April 5: 18. 